\title{
Adsorption isotherm, kinetic modeling and mechanism of 2,4,6-trichlorophenol on coconut husk-based activated carbon
}

\author{
B.H. Hameed*, I.A.W. Tan, A.L. Ahmad \\ School of Chemical Engineering, University Science Malaysia, Engineering Campus, 14300 Nibong Tebal, Penang, Malaysia
}

Received 31 October 2007; received in revised form 7 January 2008; accepted 15 January 2008

\begin{abstract}
The adsorption characteristics of 2,4,6-trichlorophenol (TCP) on coconut husk-based activated carbon prepared under optimized conditions were evaluated. Batch adsorption studies were conducted to study the effects of various parameters such as initial concentration, agitation time and solution $\mathrm{pH}$ on TCP adsorption. Adsorption capacity was found to increase with increase in initial concentration and agitation time, while acidic $\mathrm{pH}$ was more favourable for the adsorption of TCP. Equilibrium data were analyzed by the Langmuir, Freundlich, Temkin and Redlich-Peterson models by using non-linear regression technique. The equilibrium data were best represented by the Langmuir isotherm, yielding maximum monolayer adsorption capacity of $716.10 \mathrm{mg} / \mathrm{g}$ at $30^{\circ} \mathrm{C}$. The adsorption kinetics was found to follow the pseudo-second-order kinetic model. The mechanism of the adsorption process was determined from the intraparticle diffusion model. Boyd plot revealed that the adsorption of TCP on the activated carbon was mainly governed by particle diffusion. Coconut husk-based activated carbon was shown to be an efficient adsorbent for removal of TCP from aqueous solutions.
\end{abstract}

(C) 2008 Elsevier B.V. All rights reserved.

Keywords: Coconut husk activated carbon; 2,4,6-trichlorophenol; Adsorption; Isotherm; Kinetics

\section{Introduction}

Cholorophenols are a group of chemicals in which chlorines (between one and five) have been added to phenol. The main pollution sources containing chlorophenols are the wastewaters from pesticide, paint, solvent, pharmaceutics, wood, paper and pulp industries as well as water disinfecting process [1]. Chlorophenols are weak acids, which permeate human skin by in vitro and are readily absorbed by gastro-intestinal tract [2] . 2,4,6Trichlorophenol (TCP) is a toxic, mutagenic and carcinogenic pollutant. It is found in the emissions from fossil fuel combustion, municipal waste incineration, and chlorination of water containing phenol or certain aromatic acids with hypochlorite or during disinfection of water [3]. TCP has been also reported to cause adverse effects on human nervous system and respiratory problems such as chronic bronchitis, cough and altered pulmonary function [4]. The stable $\mathrm{C}-\mathrm{Cl}$ bond and the position of chlorine atoms relative to the hydroxyl group are responsible for their toxicity and persistence in the biological environment

\footnotetext{
* Corresponding author. Tel.: +60 4599 6422; fax: +60 45941013

E-mail address: chbassim@eng.usm.my (B.H. Hameed).
}

[5]. Due to its high toxicity, carcinogenic properties, structural stabilization and persistence in the environment, the removal of TCP from the environment is crucial.

From literature, various treatment methods have been applied to remove chlorophenols from aqueous solutions, such as biological treatment using anaerobic granular sludge [1] and dead fungus [6], catalytic wet oxidation [3], adsorption technology using activated clay [4] and activated carbons prepared from various precursors $[2,7-10]$. Other treatment technologies include air stripping, incineration, ion exchange and solvent extraction. Adsorption on activated carbon is one of the most effective and widely used techniques in treating high strength and low volume of phenolic wastewaters $[2,8]$. Commercially available activated carbons like F300 granular activated carbon (Calgon Corp., Pittsburgh, PA) are used for the adsorption of chlorophenols [11]. However, the usage of activated carbon has been limited by its high cost due to the use of non-renewable and relatively expensive starting material such as coal, which is a major economic consideration [12]. This has prompted a growing research interest in the production of low cost activated carbons especially for application concerning wastewater treatment.

Recently, focus has been given on the preparation of activated carbons from agricultural by-products such as jackfruit 